\title{
Magnesium Sulfate Treatment after Transient Hypoxia-Ischemia in the Newborn Piglet Does Not Protect against Cerebral Damage
}

\author{
KIRSTY GREENWOOD, PHILIP COX, HUSEYIN MEHMET, JULIET PENRICE, PHILIP N. AMESS, \\ ERNEST B. CADY, JOHN S. WYATT, AND A. DAVID EDWARDS \\ Weston Laboratory, Division of Paediatrics, Obstetrics and Gynaecology [K.G., H.M., A.D.E.], Imperial \\ College School of Science, Technology and Medicine, Department of Histopathology [P.C.], Imperial \\ College School of Medicine, Hammersmith Hospital, London, W12 0NN, Department of Paediatrics \\ [J.P., P.N.A., J.S.W.], Royal Free and University College Medical School, London, WC1E 6JJ, and \\ Department of Medical Physics and Bioengineering [E.B.C.], University College London and University \\ College London Hospitals' Trust, London, WC1E 6JA, U.K.
}

\begin{abstract}
ABST
Transient perinatal hypoxia-ischemia (HI) can lead to delayed
cerebral damage beginning $8-24 \mathrm{~h}$ after resuscitation. Cerebro-
protective therapies applied soon after HI may thus reduce the
severity of brain injury. We have previously shown that $\mathrm{MgSO}_{4}$
administration to newborn piglets after HI fails to prevent the
delayed global impairment in cerebral energy metabolism char-
acteristic of severe brain damage. However, high extracellular
concentrations of magnesium ions have been found to prevent
specific excitotoxic neural cell death in vivo and in vitro. This
study therefore examined the hypothesis that $\mathrm{MgSO}{ }_{4}$ adminis-
tration after HI reduces damage in some regions of the brain even
though global energy metabolism is unaffected. Twelve newborn
piglets were subjected to global cerebral HI by transient occlu-
sion of both common carotid arteries and reduction of the
inspired oxygen fraction to 0.12 until cerebral high-energy phos-
phates, measured by magnetic resonance spectroscopy, were
significantly depleted. Subjects were randomly assigned to two
groups of six: the first received MgSO ${ }_{4}$ (three doses, 400 mg/kg
1 h after resuscitation and $200 \mathrm{mg} / \mathrm{kg}$ at 12 and $24 \mathrm{~h}$ ), and the
second received placebo infusions. At $48 \mathrm{~h}$ after the start of the
\end{abstract}
experiment, the piglets were killed and their brains were perfused, fixed, and embedded in paraffin wax. Five-micrometer sections were stained with hematoxylin and eosin to allow semiquantitative analysis of the severity and extent of injury to the hippocampus, cerebellum, cerebral cortex, caudate nucleus, thalamus, and striatum and the white matter tracts. There was no difference in the severity of tissue damage between the $\mathrm{MgSO}_{4}$ treated group and the placebo-treated animals in any brain region. (Pediatr Res 48: 346-350, 2000)

Abbreviations
EPP, exchangeable phosphate pool
H\&E, hematoxylin and eosin
HI, hypoxia-ischemia
MRS, magnetic resonance spectroscopy
NMDA, $N$-methyl-D-aspartate
NTP, nucleotide triphosphate
PCr, phosphocreatine
Pi, inorganic phosphate

Perinatal HI is a significant cause of neonatal mortality and permanent neurodevelopmental impairments (1). Studies using ${ }^{31} \mathrm{P}$ MRS have demonstrated that newborn infants suffering global HI related to birth asphyxia possessed apparently normal cerebral energy metabolism soon after resuscitation. However, oxidative phosphorylation, measured by a fall in [PCr]/ [Pi], became impaired about $24 \mathrm{~h}$ later (2). The magnitude of

Received October 6, 1998; accepted June 15, 1999.

Correspondence and reprint requests: A.D. Edwards, MD, Division of Paediatrics, Obstetrics and Gynaecology, Imperial College School of Science, Technology and Medicine, Hammersmith Hospital, Du Cane Road, London W12 0NN, U.K.

Supported by The Sir Jules Thorn Charitable Trust, the Medical Research Council, UK, the Wellcome Trust, University College London Hospitals Trust, and Garfield Weston Foundation. this delayed injury predicted both the severity of later neurodevelopmental impairment and reduced brain growth $(2,3)$. This sequence has been demonstrated in newborn piglets subjected to transient global HI (4) and developing rats experiencing focal damage after unilateral carotid artery occlusion (5).

The period before delayed injury presents a possible window of opportunity for therapeutic intervention to reduce neural damage. Many potential therapies are under investigation; for example, in newborn piglets moderate hypothermia applied soon after HI reduces both the decline in cerebral energy metabolism and the amount of cell death in the brain (6). Administration of $\mathrm{MgSO}_{4}$ has been suggested as a possible cerebroprotective agent because magnesium ions block the 
NMDA channel and can therefore act as potent antagonists of glutamate neurotoxicity in cell culture (7). Furthermore, administration of $\mathrm{MgSO}_{4}$ reduces cerebral infarction in animals subjected to direct injection of glutamate agonists into the brain (8).

Previous results from this study demonstrated that administration of $\mathrm{MgSO}_{4}$ failed to reduce the delayed decline in cerebral energy metabolism after $\mathrm{HI}$ in newborn piglets (9). However, from the apparent success of $\mathrm{MgSO}_{4}$ in protection against cortical injury induced by glutamate agonists (10), we surmised that local neuroprotective effects might also be expected in cerebral HI, even if global energy metabolism was unaffected. Consequently, this study used brain tissue from the animals previously studied by MRS to examine the hypothesis that $\mathrm{MgSO}_{4}$ administration after $\mathrm{HI}$ reduced damage in defined regions of the brain.

\section{METHODS}

These experiments were performed under Home Office license and according to UK guidelines.

Subjects. Twelve healthy Large White piglets, born at term [mean $( \pm \mathrm{SD})$ gestation, $116 \pm 2 \mathrm{~d}]$ and weighing $1.75 \pm 0.33$ $\mathrm{kg}$, were studied on the first day of life. Full details of the maintenance and monitoring of the piglets have been given previously $(4,6)$. Briefly, after sedation with i.m. midazolam $(0.2 \mathrm{mg} / \mathrm{kg})$, anesthesia was induced with $5 \%$ isoflurane followed by tracheostomy and ventilation with nitrous oxide, oxygen, and isoflurane $(<1.5 \%)$. Full intensive care was maintained with continuous monitoring of vital functions and intermittent observations of a range of biochemical variables. The piglets were maintained inside the bore of a magnetic resonance spectrometer (Bruker Biospec, Karlsbrugh, Germany), which allowed continuous observation of cerebral energy metabolism by MRS.

Acute cerebral HI. After stable baseline observations, each piglet underwent a cerebral $\mathrm{HI}$ insult achieved by reducing the inspired oxygen fraction to 0.12 and transient carotid artery occlusion. This was continued until severe cerebral energy failure developed, as shown by almost total depletion of $\mathrm{PCr}$, and a fall in $[\mathrm{NTP}] /[\mathrm{EPP}]$, the ratio of nucleotide triphosphate to the exchangeable phosphate pool, which consists of [NTP] $+[\mathrm{PCr}]+[\mathrm{Pi}]$ to less than a third of baseline. The ratio of $[\mathrm{NTP}] /[\mathrm{EPP}]$ gives the number of phosphate equivalents available from NTP. It is the best available measure of acute high-energy phosphate depletion and correlates well with the severity of each cerebral injury (11). The animals were then resuscitated, and observations by MRS and of systemic variables continued until $48 \mathrm{~h}$ after resuscitation.

$\mathbf{M g S O}_{4}$ administration. The 12 piglets were randomly assigned, blind to the investigators, into two groups of six, one of which received $\mathrm{MgSO}_{4}$ and the other placebo $(0.9 \% \mathrm{NaCl})$. Three doses of $12.5 \% \mathrm{MgSO}_{4} \cdot 7 \mathrm{H}_{2} \mathrm{O}$ solution $\left(0.5 \mathrm{mmol} \mathrm{\textrm {Mg } ^ { 2 + }}\right.$ per $\mathrm{mL}$ ) were administered: $400 \mathrm{mg} / \mathrm{kg} \mathrm{MgSO}_{4} \cdot 7 \mathrm{H}_{2} \mathrm{O} 1 \mathrm{~h}$ after resuscitation, and $200 \mathrm{mg} / \mathrm{kg} 12$ and $24 \mathrm{~h}$ later. Doses were infused slowly, the first for $20 \mathrm{~min}$, and the latter two for 10 $\min$.
Neuropathology. At the end of the study, the animals were killed by overdose of anesthetic. The brains were perfusionfixed using $1 \%$ paraformaldehyde (Sigma, Poole, U.K.) in PBS, fixed in $1 \%$ paraformaldehyde for a minimum of $16 \mathrm{~h}$, and stored in $15 \%$ sucrose containing $0.02 \%$ sodium azide at $4^{\circ} \mathrm{C}$. The brains were then cut into left and right hemispheres, the midbrain was visualized, and two 5 -mm coronal blocks were cut through the thalamus according to a specialized anatomy atlas (12). A third block was made $5 \mathrm{~mm}$ rostral to the thalamus to include the caudate nucleus, and a final $5-\mathrm{mm}$ block was made through the cerebellum. These blocks were dehydrated and embedded in paraffin wax, and 5- $\mu \mathrm{m}$ sections were cut and fixed onto silane-coated slides by incubating overnight at $37^{\circ} \mathrm{C}$. The sections were then stained with Cole's hematoxylin (Pioneer Research Chemicals Ltd, Colchester, U.K.) and eosin (BDH Laboratory Supplies, Poole, U.K.). Stained brain sections were examined by a pathologist unaware of the experimental details (P.C.) using a Leitz orthoplan microscope with $\times 40$ NPL Fluolar objective and $\times 10$ eyepieces. Several sections were assessed from each of the four blocks. Larger structures such as cortex and the thalamus were present in two or more blocks so that multiple fields were counted in different parts of the structure. The classification of severity of injury was undertaken on identical brain regions in piglets of the same developmental stage and size. For this study, the intention was not an absolute quantitation of cell death but a comparison of the relative cell death in the two groups, and thus cell counting of total fields was not undertaken on the assumption that overall cellularity in the identical brain region would be the same. Although there were six piglets in each group, in occasional sections a specific brain region was absent (the missing region was not always from the same animal); thus, that animal could not be assessed. Consequently, the number of subjects described in the "Results" may be $<12$.

Apoptotic cells were identified using the following morphological criteria: intense, uniform nuclear basophilia with fragmentation of the nucleus into several rounded and uniformly densely basophilic masses (karryorhexis) (13). Chromatin condensation (pyknosis) is also a feature of apoptosis, but for this study only karryorhexis was used for semiquantitative analysis as this is the most distinctive feature of apoptotic cell death. As a result of this, it is likely that the amount of apoptosis is underestimated, but because both magnesium-treated and untreated groups were analyzed by the same method and karryorhexis is less open to interpretation than pyknosis, the results will be more likely to reflect a true comparison of the relative numbers of apoptotic cells between the two groups. Necrotic cells were identified by intense cytoplasmic eosinophilia accompanied by nuclear chromatin dispersion with loss of nuclear membrane integrity (nucleolysis) (14).

Brain regions examined for apoptotic and necrotic cell death were the cerebellar cortex, caudate nucleus, corpus striatum, thalamus, cerebral cortex (frontal, parietal, and temporal lobes), and hippocampus (dentate and hippocampal gyri). Edema, karyorrhexis, and astrocyte hypertrophy were assessed in the periventricular and subcortical white matter and the internal capsule. 
The severity of damage in each brain region was semiquantitatively measured and assigned to one of three groups:

1. No damage, with no karyorrhectic or necrotic cells visible.

2. Mild to moderate damage, with between one and five karyorrhectic or necrotic cells per field.

3. Severe damage, with greater than five karyorrhectic or necrotic cells per field.

The overall distribution and extent of severe damage in each brain was classified into one of three groups:

1. Localized damage, where less than half the areas scored had severe damage.

2. Widespread damage, where more than half the areas scored had severe damage.

3. Global damage, where all areas assessed had severe damage.

Data analysis. The severity of the $\mathrm{HI}$ insult was determined by calculating the time-integral of the depletion of $[\mathrm{NTP}] /$ [EPP] from the onset of HI until $1 \mathrm{~h}$ after resuscitation, as previously described and reported (9).

Data groups were examined for normality and for equal variance. The two groups were compared by Kruskall-Wallis ANOVA.

\section{RESULTS}

\section{Physiologic and MRS Variables}

The physiologic, MRS, and blood $\left[\mathrm{Mg}^{2+}\right]$ results have been published previously (9). In brief, there were no significant differences between the two groups of piglets for observations of a wide range of systemic and biochemical variables, including arterial $\mathrm{PO}_{2}, \mathrm{PCO}_{2}, \mathrm{pH}$, base excess, hematocrit, blood glucose, mean arterial blood pressure, heart rate, rectal and tympanic temperatures, and plasma $\mathrm{Na}^{+}, \mathrm{K}^{+}$, urea, creatinine, and lactate, either at baseline, at the end of the insult, or 2, 24, and $48 \mathrm{~h}$ after resuscitation. The mean $( \pm \mathrm{SD})$ duration of the $\mathrm{HI}$ insult was $53 \pm 32 \mathrm{~min}$. Although both groups received insults of similar severity (Fig. 1), there was no significant difference between the $\mathrm{MgSO}_{4}$-treated group and the controls in the degree of secondary energy failure (9).

\section{Descriptive Neuropathology}

Overall neuropathology. Significant damage was apparent in every brain studied, with large numbers of both apoptotic and necrotic cells, usually in multiple brain regions. However, despite some variability in the degree and extent of damage, there was no characteristic pattern that differentiated the $\mathrm{MgSO}_{4}$-treated group from the placebo group.

Regional neuropathology. All but one piglet had severe neuronal damage in the hippocampus, with higher numbers of necrotic than apoptotic cells in the dentate and hippocampal gyri. The cerebellum was badly damaged in all but one of the piglets studied, with necrosis evident in a large proportion of cells in the Purkinje layer and severe apoptosis of neurons in the granule layer. In the caudate nucleus, thalamus, and striatum, a wide range of neuronal damage was observed in indi-

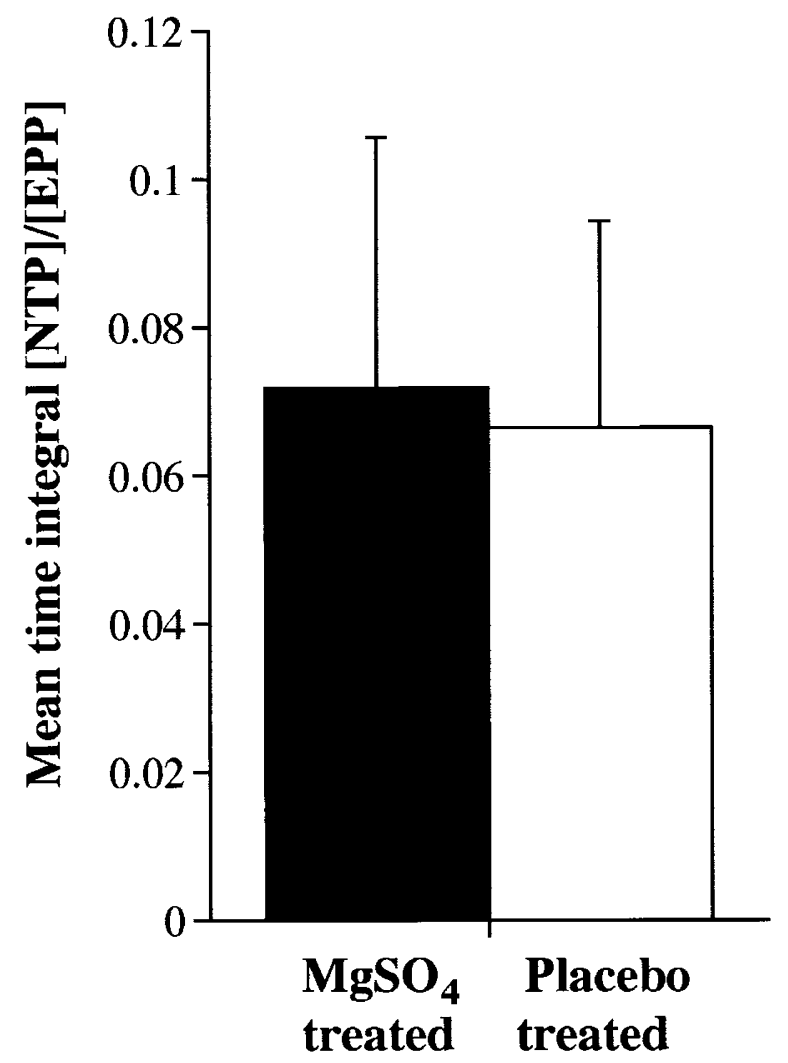

Figure 1. Effect of $\mathrm{MgSO}_{4}$ treatment on primary energy failure after cerebral $\mathrm{HI}$. Mean time integral [NTP]/[EPP] in the $\mathrm{MgSO}_{4}$-treated piglet group (black bar) and placebo-treated group (white bar) showing that there was no significant difference between the two groups in the severity of the initial cerebral energy failure. The greater the value of $[\mathrm{NTP}] /[\mathrm{EPP}]$, the more severe the NTP depletion.

vidual animals; however, there was no significant difference between placebo-treated animals and those receiving $\mathrm{MgSO}_{4}$.

In both groups of animals, the frontal cortex was severely damaged. In all piglets in the $\mathrm{MgSO}_{4}$-treatment group, this region contained high numbers of necrotic neurons with varying numbers of apoptotic cells. A similar pattern was observed in the parietal and temporal lobes. Significant numbers of dead cells were observed in all white matter tracts studied, with apoptosis much more apparent than necrosis. Dead cells were most likely to be astrocytes or oligodendrocytes. A broad spectrum of injury could be observed in the internal capsule and the subcortical and periventricular white matter tracts, with some animals showing evidence of astrocytosis or edema.

Significantly, there was no difference between the two treatment groups in the amount of cell death in any of the regions examined.

\section{Semiquantitative Neuropathology}

The extent of injury in individual regions related to the intensity of the $\mathrm{HI}$ insult is shown in Figure 2, with the results of semiquantitative scoring of the overall extent of severe damage given in Figure 3. Data groups were frequently nonGaussian, and the $\mathrm{MgSO}_{4}$-treated piglets were thus compared to the placebo group by Kruskall-Wallis ANOVA. Statistical analysis revealed no significant difference between the groups, 


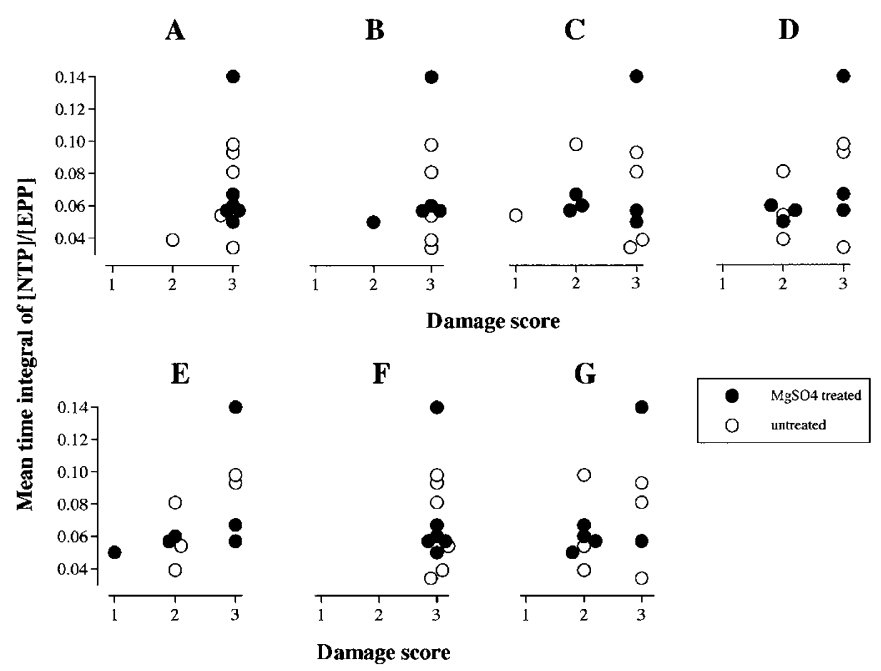

Figure 2. $\mathrm{MgSO}_{4}$ effects on the relationship between primary energy failure and cerebral damage after cerebral HI. Values for the time integral of [NTP]/ [EPP] in individual subjects, related to histologic damage, comparing the $\mathrm{MgSO}_{4}$-treated (filled circles) and untreated piglets (unfilled circles) in the cerebellum $(A)$, hippocampus $(B)$, caudate nucleus $(C)$, striatum $(D)$, thalamus $(E)$, cerebral cortex $(F)$, and white matter tracts $(G)$. The severity of damage (damage score) was graded 1, no damage; 2 , mild to moderate damage; and 3, severe damage. The mean time integral values used were from Penrice et al. (9).

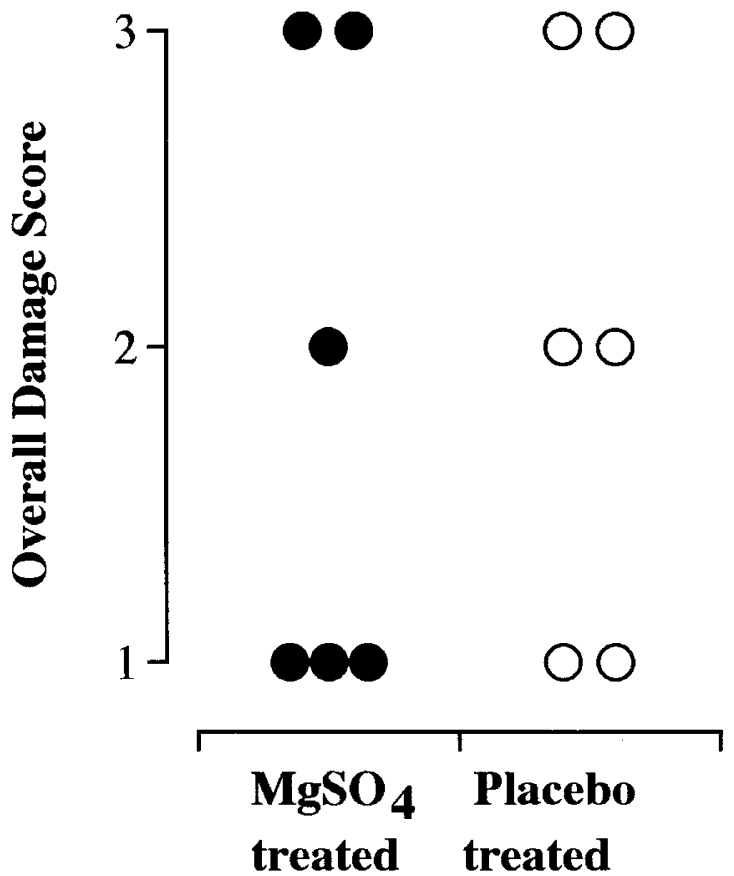

Figure 3. Comparison of overall damage score for $\mathrm{MgSO}_{4}$-treated and placebo groups. Data for individual piglets are presented according to the severity of damage, comparing $\mathrm{MgSO}_{4}$-treated (filled circles) with untreated subjects (unfilled circles). The severity of damage (damage score) was graded 1, localized damage; 2, widespread damage; and 3, global damage.

either in the severity of damage in any brain area or in the overall extent of severe injury.

\section{DISCUSSION}

In this study, there was no difference in the overall extent of severe injury between $\mathrm{MgSO}_{4^{-}}$and placebo-treated groups, which is thus consistent with earlier results from this study showing a lack of correlation between delayed energy failure and $\mathrm{MgSO}_{4}$ treatment. The present results also show that there was no localized protective effect caused by $\mathrm{MgSO}_{4}$ in the brain regions studied. The regional damage was similar to that observed after HI injury in previous studies (15).

In any study with negative results, it is possible that a larger study group might detect a difference, and it is not possible to completely rule out this type II error as the reason for finding no effect. However, using this model of HI, studies with numbers of animals similar to the present study have been able to show significant differences in brain injury when moderate hypothermia is applied after HI (16). It is thus reasonable to conclude that even if the present study failed to detect a minor protective effect of $\mathrm{MgSO}_{4}$, this effect must be significantly smaller than that of hypothermia.

The use of MRS allowed us to describe the severity of $\mathrm{HI}$ in each individual animal by a precise measurement of the time integral of the fall in [NTP]/[EPP]. Although it was not a part of this study to relate the severity of the decline in [NTP]/[EPP] to histologic data, we saw considerable variability in the fall of $[\mathrm{NTP}] /[\mathrm{EPP}]$, and also that, in general, more severe energy deprivation was associated with more severe histologic injury in all brain areas. For the present study, however, it is sufficient to note that there was no difference in the average severity of $\mathrm{HI}$ between the groups.

$\mathrm{MgSO}_{4}$ is thought to be potentially neuroprotective as $\mathrm{Mg}^{2+}$ ions gate the NMDA receptor and so reduce the $\mathrm{Ca}^{2+}$ influx that can trigger cell death $(10,17)$. In cell culture systems, high extracellular $\left[\mathrm{Mg}^{2+}\right]$ protects against glutamatergic cell death (7). In vivo, $\mathrm{MgSO}_{4}$ can reduce neuronal death if administered after specific types of brain injury. For example, multiple doses of $\mathrm{MgSO}_{4}$ reduced neuronal loss significantly in 7-d-old rats after an intracerebroventricular injection of NMDA (8). Similar results were observed in 5-d-old mice given an injection of $\mathrm{MgSO}_{4}$ either before or 10 min after intracerebroventricular ibotenate, a glutamatergic agonist (10). $\mathrm{MgSO}_{4}$ was also protective when administered $30 \mathrm{~min}$ after trauma in a model of severe traumatic brain injury in rats (18). In studies that have looked specifically at $\mathrm{HI}, \mathrm{MgSO}_{4}$ alone has not been so successful (19), although a combination of $\mathrm{MgSO}_{4}$ and oxygen free radical scavengers given immediately after a unilateral carotid ligation and hypoxia in 7-d-old rats did reduce cerebral damage (20).

The lack of attenuation of brain damage in the present study may be related to several factors. It might be that insufficient $\mathrm{Mg}^{2+}$ reached the glutamatergic synaptic cleft and so $\mathrm{Ca}^{2+}$ influx was not prevented. In two infants with birth asphyxia, $\left[\mathrm{Mg}^{2+}\right]$ in the cerebrospinal fluid was less than plasma levels despite the fact that normally cerebrospinal fluid $\left[\mathrm{Mg}^{2+}\right]$ is $30 \%$ higher than in plasma (17). This suggests that there may be limited $\mathrm{Mg}^{2+}$ transfer across the blood-brain barrier after $\mathrm{HI}$ injury. Increasing doses to achieve higher plasma $\left[\mathrm{Mg}^{2+}\right]$ might be unsafe for infants as heart rate and mean arterial blood pressure fall with $\mathrm{MgSO}_{4}$ administration (9), although continuous infusion of $\mathrm{MgSO}_{4}$ in piglets (21) and infants (22) may minimize these adverse effects. 
Another possibility for the lack of protective effect of $\mathrm{MgSO}_{4}$ is that unlike a single injection of glutamate agonist, which is specific and can be blocked by $\mathrm{Mg}^{2+}$ ions competing at a single class of receptors, $\mathrm{HI}$ triggers several biochemical reactions on which $\mathrm{MgSO}_{4}$ has no effect, such as free radical formation (19). Therefore, a blockade of NMDA receptors during reperfusion might be overwhelmed by the adverse effects of these other reactions. Lastly, it may be that glutamate release occurs before the first dose of magnesium can be administered. Consistent with this possibility, Thoresen et al. (23) have shown that in newborn piglets, cerebral HI causes an immediate increase in glutamate levels, which return to preinjury levels within $2 \mathrm{~h}$. The absence of neuroprotective effects of $\mathrm{MgSO}_{4}$ has also been reported in a well-established rat model of perinatal HI; in the 7-d-old rat, magnesium treatment after perinatal HI was not markedly neuroprotective for striatal medium spiny neurons, a population that abundantly expresses NMDA receptors (24).

In conclusion, this study found no evidence that $\mathrm{MgSO}_{4}$ administration beginning $1 \mathrm{~h}$ after $\mathrm{HI}$ ameliorates the severity, extent, or distribution of cerebral injury in the newborn piglet.

\section{REFERENCES}

1. Volpe JJ 1995 Neurology of the Newborn, 3rd Ed. WB Saunders, Philadelphia, pp $279-314$

2. Azzopardi D, Wyatt JS, Cady EB, Delpy DT, Baudin J, Stewart AL, Hope PL, Hamilton PA, Reynolds EO 1989 Prognosis of newborn infants with hypoxicischemic brain injury assessed by phosphorus magnetic resonance spectroscopy. Pediatr Res 25:445-451

3. Roth SC, Edwards AD, Cady EB, Delpy DT, Wyatt JS, Azzopardi D, Baudin J, Townsend J, Stewart AL, Reynolds EOR 1992 Relation between cerebral oxidative metabolism following birth asphyxia and neurodevelopmental outcome and brain growth at one year. Dev Med Child Neurol 34:285-295

4. Lorek A, Takei Y, Cady EB, Wyatt JS, Penrice J, Edwards AD, Peebles D, Wylezinska M, Owen-Reece H, Kirkbride V, Cooper CE, Aldridge RF, Roth SC, Brown G, Delpy DT, Reynolds EOR 1994 Delayed ("secondary") cerebral energy failure after acute hypoxia-ischemia in the newborn piglet: continuous 48-hour studies by phosphorus magnetic resonance spectroscopy. Pediatr Res 36:699-706

5. Blumberg RM, Cady EB, Wigglesworth JS, McKenzie JE, Edwards AD 1996 Relation between delayed impairment of cerebral energy metabolism and infarction following transient focal hypoxia-ischaemia in the developing brain. Exp Brain Res 113:130-137

6. Thoresen M, Penrice J, Lorek A, Cady EB, Wylezinska M, Kirkbride V, Cooper CE, Brown GC, Edwards AD, Wyatt JS, Reynolds EOR 1995 Mild hypothermia after severe transient cerebral hypoxia-ischaemia ameliorates delayed cerebral energy failure in the newborn piglet. Pediatr Res 37:667-670

7. Rose K, Christine CW, Choi DW 1990 Magnesium removal induces paroxysmal neuronal firing and NMDA receptor-mediated neuronal degeneration in cortical cultures. Neurosci Lett 115:313-317

8. McDonald JW, Silverstein FS, Johnston MV 1990 Magnesium reduces $N$-methyl-Daspartate (NMDA)-mediated brain injury in perinatal rats. Neurosci Lett 109:234238

9. Penrice J, Amess PN, Punwani S, Wylezinska M, Tyszczuk L, D’Souza P, Edwards AD, Cady EB, Wyatt JS Reynolds EOR 1997 Magnesium sulfate after transient hypoxia-ischemia fails to prevent delayed cerebral energy failure in the newborn piglet. Pediatr Res 41:443-447

10. Marret S, Gressens P, Gadisseux J-F, Evrard P 1995 Prevention by magnesium of excitotoxic neuronal death in the developing brain: an animal model for clinical intervention studies. Dev Med Child Neurol 37:473-484

11. Mehmet H, Yue X, Squier MV, Lorek A, Cady E, Penrice J, Sarraf C, Wylezinska M, Kirkbride V, Cooper C, Brown GC, Wyatt JS, Reynolds EOR, Edwards AD 1994 Increased apoptosis in the cingulate sulcus of newborn piglets following transient hypoxia-ischaemia is related to the degree of high energy phosphate depletion during insult. Neurosci Lett 181:121-125

12. Yoshikawa Tetsuo 1968 Part V. The brain of the pig. In: Atlas of the Brains of Domestic Animals. University of Tokyo Press, Tokyo, pp 6-8, 16

13. Wyllie AH, Duvall E 1992 Oxford Textbook of Pathology. Vol 26. Oxford University Press, Oxford, pp 141-193

14. Hockenbery D 1995 Defining apoptosis. Am J Pathol 146:16-19

15. Yue X, Mehmet H, Penrice J, Cooper C, Cady E, Wyatt JS, Reynolds EOR, Edwards $\mathrm{AD}$, Squier MV 1997 Apoptosis and necrosis in the newborn piglet brain following transient hypoxia-ischaemia. Neuropathol Appl Neurobiol 23:16-25

16. Edwards AD, Yue X, Squier MV, Thoresen M, Cady EB, Penrice J, Cooper CE, Wyatt JS, Reynolds EOR, Mehmet H 1995 Specific inhibition of apoptosis after cerebral hypoxia-ischaemia by moderate post-insult hypothermia. Biochem Biophys Res Commun 217:1193-1199

17. Levene M, Blennow M, Whitelaw A, Hanko E, Fellman V, Hartley R 1995 Acute effects of two different doses of magnesium sulphate in infants with birth asphyxia. Arch Dis Child 73:F174-F177

18. Heath DL, Vink R 1997 Magnesium sulphate improves neurologic outcome following severe closed head injury in rats. Neurosci Lett 228:175-178

19. Gluckman PD, Williams CE 1992 When and why do brain cells die? Dev Med Child Neurol 34:1010-1014

20. Thordstein M, Bågenholm R, Thiringer K, Kjellmar I 1993 Scavengers of free oxygen radicals with magnesium ameliorate perinatal hypoxic-ischemic brain damage in the rat. Pediatr Res 34:23-26

21. Hoffman DJ, Marro PJ, McGowan JE, Mishra OP, Delivoria-Papadopoulis M 1994 Protective effect of $\mathrm{MgSO}_{4}$ infusion on NMDA receptor binding characteristics during cerebral cortical hypoxia in the newborn piglet. Brain Res 644:144-149

22. Wu TJ, Teng RJ, Yau K-IT 1995 Persistent pulmonary hypertension of the newborn treated with magnesium sulfate in premature neonates. Pediatrics 96:472-474

23. Thoresen M, Satas S, Puka-Sundvall M, Whitelaw A, Hallstrom A, Loberg EM, Ungerstedt U, Steen PA, Hagberg H 1997 Post-hypoxic hypothermia reduces cerebrocortical release of NO and excitotoxins. Neuroreport 8:3359-3362

24. Galvin KA, Oorschot DE 1998 Post injury magnesium sulfate treatment is not markedly neuroprotective for striatal medium spiny neurons after perinatal hypoxia/ ischemia in the rat. Pediatr Res 44:740-745 